\title{
Interstitial and cerebrospinal fluid exchanging process revealed by phase alternate labeling with null recovery MRI
}

Anna M. $\mathrm{Li}^{1}$, Jiadi $\mathrm{Xu}^{1,2^{*}}$

${ }^{1}$ F.M. Kirby Research Center for Functional Brain Imaging, Kennedy Krieger Research Institute, Baltimore, MD, USA

${ }^{2}$ Russell H. Morgan Department of Radiology and Radiological Science, The Johns Hopkins University School of Medicine, Baltimore, MD, USA

\section{*Corresponding Author:}

Jiadi Xu, Ph.D.

Kennedy Krieger Institute

The Johns Hopkins University School of Medicine

707 N. Broadway

Baltimore, MD, 21205

E-mail: xuj@kennedykrieger.org

Tel: 443-923-9572

Fax: 443-923-9505

Grant support from NIH: P41EB031771, R01HL149742, R21AG065794, and R21NS118079,

Running title: Phase alternate labeling with null recovery MRI

Rapid Communication word limitation: 3500 words, 7 (figures plus tables)

Submit to Magnetic Resonance in Medicine 


\begin{abstract}
Purpose: To develop Phase Alternate LAbeling with Null recovery (PALAN) MRI methods for the quantification of interstitial to cerebrospinal fluid flow (ICF) and cerebrospinal to interstitial fluid flow (CIF) in the brain.

Method: In both $\mathrm{T}_{1}$-PALAN and apparent diffusion coefficient (ADC)-PALAN MRI methods, the cerebrospinal fluid (CSF) signal was nulled, while the residual interstitial fluid (ISF) was labeled by alternating the phase of pulses. ICF was extracted from the difference between the recovery curves of CSF with and without labeling. Similarly, CIF was measured by the $\mathrm{T}_{2}$-PALAN MRI method by labeling CSF, which took advance of the significant $\mathrm{T}_{2}$ difference between CSF and parenchyma.

Results: Both $\mathrm{T}_{1}$-PALAN and ADC-PALAN observed a rapid occurrence of ICF at $67 \pm 56 \mathrm{~ms}$ and $13 \pm 2 \mathrm{~ms}$ interstitial fluid transit times, respectively. ICF signal peaked at $1.5 \mathrm{~s}$ for both methods. ICF was $1153 \pm 270 \mathrm{ml} / 100 \mathrm{ml} / \mathrm{min}$ with $\mathrm{T}_{1}$-PALAN in the third and lateral ventricles, which was higher than $891 \pm 60 \mathrm{ml} / 100 \mathrm{ml} / \mathrm{min}$ obtained by ADC-PALAN. The results of the $\mathrm{T}_{2}$-PALAN suggested the ISF exchanging from ependymal layer to the parenchyma was extremely slow.

Conclusion: The PALAN methods are suitable tools to study ISF and CSF flow kinetics in the brain.
\end{abstract}

\title{
Key Words:
}

interstitial fluid (ISF), cerebrospinal fluid (CSF), Phase alternate labeling with null recovery (PALAN), glymphatic system, interstitial fluid and cerebrospinal fluid flow (ICF), cerebrospinal and interstitial fluid flow (CIF) 


\section{Introduction}

Cerebrospinal fluid (CSF) plays an essential role in maintaining the homeostasis of the central nervous system, providing buoyancy to the brain (1), serving as an important route for the removal of a variety of waste products produced by cellular metabolism (2). Its circulation has been the subject of speculation and experiment for more than one hundred years. However, its formation and circulation are still under debate. (3-9) Conventionally, it is believed that the anterior choroidal arterial blood secretes CSF via choroid plexuses (CP) inside the brain ventricles (80-90\%), and CSF flows unidirectionally along subarachnoid spaces to be absorbed into venous sinuses. $(3,10-$ 12) Some other pieces of evidence supported that CSF continuously exchanges with the interstitial fluid (ISF) in its surrounding brain parenchyma, which depends on hydrostatic and osmotic forces, i.e. the transependymal flow. (13-17) Notably, the recent rediscovery of the brain lymphatic system, dubbed as the glymphatic system, suggested a portion of the subarachnoid CSF recirculates through the brain parenchyma and exchanges with the ISF and then flow back to CSF (18-21). The glymphatic system has drawn intensive attention since its discovery because it appeared to clear off soluble amyloid-beta $(A \beta)$ from the brain parenchyma (22-25). Consequently, it is crucial to develop a clinically useful prognostic tool for ISF-CSF exchange measurement that can be used for the diagnosis and evaluation of brain diseases. Many non-invasion MRI methods, diffusionbased method $(26,27)$, and the time-of-flight-based MRI method (28) were implemented to examine the bulk flow inside the ventricles and glymphatic vessels. However, examining CSF and ISF exchanging process still relied on MRI contrast agents such as the intra-cranial $(19,29-32)$ or intrathecal injection (33-35) of gadolinium-based contrast agents and intravenous D-glucose infusion. (36,37) Contrast agent-based MRI methods are far from ideal for routine and repeated measurements on patients.

The $\mathrm{T}_{1}, \mathrm{~T}_{2}$, and apparent diffusion coefficient (ADC) are significantly different between $\operatorname{CSF}\left(\mathrm{T}_{1}=3.0 \mathrm{~s}, \mathrm{~T}_{2}=300 \mathrm{~ms}\right.$ at $\left.11.7 \mathrm{~T} ; \mathrm{ADC}=3 \mu \mathrm{m}^{2} / \mathrm{ms}\right)$ and ISF $\left(\mathrm{T}_{1}=1.8 \mathrm{~s}, \mathrm{~T}_{2}=40 \mathrm{~ms}\right.$ at $11.7 \mathrm{~T}$; $\left.\mathrm{ADC}=0.7 \mu \mathrm{m}^{2} / \mathrm{ms}\right) .(36,38)$ In principle, $\mathrm{T}_{1}, \mathrm{~T}_{2}$, or ADC can selectively label either CSF or ISF to monitor the ISF-CSF exchange process. However, in practice, it is a challenge to label CSF without attenuate ISF and vice versa. In the current study, we proposed a novel MRI strategy, dubbed as Phase Alternate LAbeling with Null recovery (PALAN), that null one of the components (ISF or CSF) and label the other component (CSF or ISF) by flipping the phase of pulses. The ISF-CSF exchanging process shaped the recovery curve of CSF or ISF. A strategy closely resembles the 
flow-sensitive alternating inversion recovery arterial spin labeling (ASL) method. (39) ICF measured via $T_{1}$ and $A D C$ difference and CIF measured via $T_{2}$ difference are named $T_{1}-P A L A N$, ADC-PALAN, and $\mathrm{T}_{2}$-PALAN, respectively. This series of quantitative PALAN methods provide novel tools to further understand CSF and ISF exchanging processes in the brain.

\section{Methods}

\section{MRI experiments}

The study was carried out under the approval of Johns Hopkins University animal care and use. For this study, ten female mice (C57BL/6J) aged 11-12 months were purchased from Jackson laboratory. All MRI experiments were performed on a horizontal bore 11.7 T Bruker Biospec system (Bruker, Ettlingen, Germany). A $72 \mathrm{~mm}$ quadrature volume resonator and a $2 \times 2$ mouse phased array coil was used as a transmitter and receiver. All animals were anesthetized using 2\% isoflurane in medical air, followed by $1 \%$ to $1.5 \%$ isoflurane for maintenance during the MRI scan. The respiratory rate was monitored via a pressure sensor (SAII, Stony Brook, NY, USA) and maintained at 70-90 breaths per minute. The $\mathrm{B}_{0}$ field over the image slice was adjusted using field mapping and second-order shimming.

\section{MRI Pulse Sequences}

Fig. 1a,b, and $\mathrm{c}$ show the schematic diagrams of the $\mathrm{T}_{1}, \mathrm{ADC}$, and $\mathrm{T}_{2}$-based PALAN sequences. For the $\mathrm{T}_{1}$-PALAN method, a hyperbolic secant (HS) inversion pulse (15 ms) was applied. At the CSF null inversion time $\left(T I_{\text {null, }} \mathrm{CSF}=2 \mathrm{~s}\right)$, the CSF signal was at the zero baseline while part of the ISF signal had recovered. One Z-filter composited by two 90-degree pulses

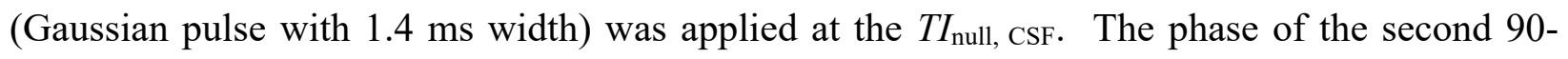
degree pulse in the Z-filter was alternated by 180-degree, flipping the parenchyma longitudinal magnetization up (control) and down (label). CSF recovery during eleven post-labeling delays (PLDs) $(0,0.1,0.2,0.4,0.6,1,1.5,2,3,4,5 \mathrm{~s})$ were recorded. The recovery from the labeling pulse was different from the original recovery curve due to the presence of ICF. Four pairs of control/label parenchyma signals were collected to measure the labeling efficiency, and eight pairs of CSF signals were recorded for the CIF measurement. A turbo spin-echo (TSE) MRI with long echo time (LE-TSE) was implemented to read the CSF signal and to suppress the parenchyma 
signal with TE $=245 \mathrm{~ms}$, pre-scan delay $5 \mathrm{~s}$, TSE factor $=96$, slice thickness $=1 \mathrm{~mm}$, a matrix size of $96 \times 96$, and a resolution of $0.17 \times 0.17 \mathrm{~mm}^{2}$.

ADC-PALAN method, much like the $\mathrm{T}_{1}$-PALAN method, can also extract ICF. Instead of applying one $\mathrm{T}_{1}$ preparation module, an improved motion-sensitized driven-equilibrium (iMSDE) module (40) was applied to suppress the CSF signal with high b values $\left(2100 \mathrm{~s} / \mathrm{mm}^{2}\right)$, but left some residual parenchyma signal. In our study, the total iMSDE module was $30 \mathrm{~ms}$, the gradient length was $3 \mathrm{~ms}$. Mao pulses (41) with $6 \mathrm{~ms}$ width was used for the 180-degree pules and Gaussian pulses (1.4 ms width) were used for the two 90-degree pulses in the iMSDE module. The phase of the second 90-degree pulse in the iMSDE module was alternated by 180 -degree to obtain the control and label images.

In the $\mathrm{T}_{1}$-PALAN and ADC-PALAN multi-PLD studies, a single axis slice was collected at $-0.7 \mathrm{~mm}$ from the anterior commissure (AC) to cover the left ventricles (LV) and third ventricle $(3 \mathrm{~V})$. Common belief states that $\mathrm{CP}$ is found in the caudal lateral ventricles. $(42,43)$ To determine CSF contributions from CP to ventricles in $\mathrm{T}_{1}$-PALAN and ADC-PALAN methods, we collected two high-resolution single PLD (1.5 s) slices (-0.7 and $0.9 \mathrm{~mm}$ from AC). ICF maps that covered the rostral and caudal LV $(n=5)$ were obtained. High-resolution $\mathrm{T}_{2}$ weighted images with a long TE turbo spin-echo (LE-TSE) sequence determined the CP locations. The scan time for each LETSE experiment was 13 minutes with $\mathrm{TR} / \mathrm{TE}=6 \mathrm{~s} / 106 \mathrm{~ms}$, RARE factor $=32$, slice thickness $=0.5$ $\mathrm{mm}$, a matrix size of $256 \times 256$ within a FOV of $16 \times 16 \mathrm{~mm}^{2}$.

The measurement of CSF backflow from ventricles to parenchyma, i.e., CIF, was achieved with the $\mathrm{T}_{2}$-PALAN method. Carr-Purcell-Meiboom-Gill (CPMG) module was used in the $\mathrm{T}_{2}$ PALAN to null the parenchyma ISF signal. The CIF process modulated the recovery curve of parenchyma. The label and control images were collected by alternating the phase of the second 90-degree pulse at the end of the CPMG module by 180-degree. TSE with short TE (TE $=5 \mathrm{~ms})$ was used to acquire parenchyma MRI images with a pre-scan delay of $5 \mathrm{~s}$, TSE factor $=16$, slice thickness $=1.5 \mathrm{~mm}, \mathrm{FOV}=1.6 \times 1.6 \mathrm{~mm}^{2}$. A matrix size of $32 \times 32$ was used for the CIF kinetic curve measurement with four pairs of control/label images, and a matrix size of $64 \times 64$ was used for the high-resolution CIF images with 32 pairs of control/label images. The total experimental time for the high-resolution CIF images was 31 minutes. 9 PLDs $(0,0.5,1,1.5,2,2.5,3$, 4, and 6 s) were acquired for the CSF labeling efficiency measurement and the CIF buildup curves with the $\mathrm{T}_{2}$-PALAN method. In the $\mathrm{T}_{2}$-PALAN multi-PLD studies, a single axis slice was collected at -0.7 
$\mathrm{mm}$ from $\mathrm{AC}$ for the CSF optimization, and the slice at $-4.1 \mathrm{~mm}$ from $\mathrm{AC}$ was used for the parenchyma signal optimization. Two slices (-0.7 and $-4.1 \mathrm{~mm}$ from AC) were collected for the high-resolution single PLD (1.5s) CIF maps.

\section{Data Analysis}

All MRI images were processed using custom-written MATLAB scripts (MathWorks, R2020a). The ICF $\left(\Delta S_{C S F}\right)$ or CIF signals $\left(\Delta S_{\text {Parenchyma }}\right)$ were calculated by subtracting the label and control images following

$$
\Delta S_{C S F / \text { parenchyma }}=\left(S_{\text {control }}-S_{\text {label }}\right) / S_{0}
$$

The $\mathrm{S}_{0}$ images were collected by setting $\mathrm{PLD}=10 \mathrm{~s}$ for parenchyma and $15 \mathrm{~s}$ for CSF in all PALAN methods.

The recovery of the parenchyma signal in the $\mathrm{T}_{1}$-PALAN and ADC-PALAN after the $\mathrm{T}_{1}$ or iMSDE preparation module can be described as

$$
\begin{array}{ll}
S_{\text {parenchyma }}^{\text {control }}=S_{0} \mid 1-(1-\alpha) e^{-P L D \cdot R_{1 I S F}} & (\text { phase }:-x) \\
S_{\text {parenchyma }}^{\text {label }}=S_{0} \mid 1-(1+\alpha) e^{-P L D \cdot R_{1 I S F} \mid} & (\text { phase }:+x)
\end{array}
$$

where $\alpha$ was the parenchyma signal after the Z-filter, i.e., the labeling efficiency. $R_{1 I S F}$ was the $\mathrm{T}_{1}$ relaxation rate of the parenchyma. In practice, nonzero noise background was present in the MRI image due to the magnitude Rician noise. Therefore, the reliable way of extracting the labeling efficiency was fitting the difference image $\left(S_{\text {parenchyma }}^{\text {control }}-S_{\text {parenchyma }}^{\text {label }}\right) / S_{0}$ following

$$
\Delta S_{\text {parenchyma }}=\left[\left|1-(1-\alpha) e^{-P L D \cdot R_{1 I S F}}\right|-\mid 1-(1+\alpha) e^{-P L D \cdot R_{1 I S F} \mid}\right]
$$

Similarly, the difference between the two CSF recovery curves after the CPMG module in the $\mathrm{T}_{2}$ PALAN method was given by

$$
\begin{gathered}
\Delta S_{C S F}=\left(S_{C S F}^{\text {control }}-S_{C S F}^{\text {label }}\right) / S_{0} \\
=\left[\left|1-(1-\alpha) e^{-P L D \cdot R_{1} C S F}\right|-\mid 1-(1+\alpha) e^{-P L D \cdot R_{1 C S F} \mid}\right]
\end{gathered}
$$

$R_{1 C S F}$ was the CSF $\mathrm{T}_{1}$ relaxation rate.

A standard single-compartment kinetic model was applied to quantify the ICF from the observed CSF signal reduction $\Delta S_{C S F}$, assuming instantaneous exchange of labeled spins from parenchyma to ventricles. The observed CSF signal reduction was described by the difference between the sum over the series of delivered magnetization units to CSF from ISF (the arterial 
input function, AIF) and the clearance of the magnetization by the relaxation of the CSF (the impulse residue function, IRF) (44-46).

The IRF function was given by

$$
c(t)=\left\{\begin{array}{c}
0(t<I T T) \\
2 \alpha \cdot f \cdot e^{-t R_{1} a}(t>I T T)
\end{array}\right.
$$

Where $\alpha$ was the ISF labeling efficiency of the $\mathrm{T}_{1}$ or iMSDE preparation module, $\mathrm{f}$ was the ICF flow in units of volume of ISF delivered per volume of CSF per unit time ( $\mathrm{ml} / 100 \mathrm{ml} / \mathrm{min})$. ITT was the ISF transit time, i.e., the time for ISF to reach CSF after labeling. The $R_{1 a}$ was a labeling decay rate due to the limited bolus duration.

The observed CSF reduction $\Delta S$ was the convolution of the AIF and the IRF functions, i.e.,

Then,

$$
\Delta S_{C S F}=c \otimes e^{-t R_{1} C S F}
$$

$$
\Delta S_{C S F}=\left\{\begin{array}{c}
0(P L D<I T T) \\
\frac{2 \alpha \cdot f}{R_{1 a p p}} e^{-P L D \cdot R_{1 a} a}\left(e^{(P L D-I T T) \cdot R_{1 a p p}}-1\right)(P L D>I T T)
\end{array}\right.
$$

where $R_{1 a p p}=R_{1 a}-R_{1 C S F}$. When measuring CIF rate by $\Delta S_{\text {Parenchyma }}$, the same equation can be used except the $R_{1 a p p}=R_{1 C S F}-R_{1 I S F}$ and

$$
\Delta S_{\text {Parenchyma }}=\left\{\begin{array}{cc}
0(P L D<I T T) \\
\frac{2 \alpha \cdot f}{R_{1 a p p}} e^{-P L D \cdot R_{1 C S F}}\left(e^{(P L D-I T T) \cdot R_{1 a p p}}-1\right)(P L D>I T T)
\end{array}\right.
$$

$\mathrm{f}$ was the CIF flow in units of volume of CSF delivered per gram ISF per unit time $(\mathrm{ml} / 100 \mathrm{mg} / \mathrm{min})$.

A paired-sample t-test was performed for the comparison between CIF values of the rostral and caudal LV using the MATLAB built-in function "ttest". t-test is considered statistically significant for $\mathrm{p}<0.05$ and highly significant when $\mathrm{p}<0.001$.

\section{Results}

ISF to CSF flow measured by $T_{1}-P A L A N$

The typical $\mathrm{T}_{1}$-PALAN CSF and parenchyma recovery curves, together with the ICF $\Delta S$ maps, are shown in Figs. 2(a-d). The post-labeling parenchyma signal curve shows a typical inversion recovery curve. Theoretically, the MRI signals with PLD less than $0.4 \mathrm{~s}$ were negative 
after the labeling pulse as seen from the standard inversion recovery curves, but the usage of magnitude-reconstructed images resulted in positive values. The parenchyma signal difference curves using Eq. 4 yielded the labeling efficiency of $\alpha=0.21 \pm 0.02$. The CSF recovery curves show a clear difference between control and label pulses, indicating high ICF values. The magnitude Rician noise background led to a positive CSF signal at $\mathrm{PLD}=0 \mathrm{~s}$. The CSF difference curves, i.e., ICF kinetic curves, show a clear buildup and decay pattern that peaks at PLD $=1.5 \mathrm{~s}$. Eq. 8 fitted perfectly with the curve, which gave ICF $=1153 \pm 270 \mathrm{ml} / 100 \mathrm{ml} / \mathrm{min}$, and ITT $=67 \pm 56 \mathrm{~ms}$. The ICF $\Delta S$ values for the rostral and caudal LV are $0.015 \pm 0.013$ and $0.034 \pm 0.01 \quad(p=0.022, n=5)$, respectively (Fig. 2e).

Figs. $2 \mathrm{~g}, \mathrm{~h}, \mathrm{j}$, and $\mathrm{k}$ are typical $\mathrm{T}_{1}$-PALAN control images and ICF maps of the brain ventricles. The high-resolution $\mathrm{T}_{2}$ maps shows the CP in the LV (Figs. $2 \mathrm{f}$ and $\mathrm{i}$ ), and the CP is clearly visible in the caudal LV regions. The ICF values were calculated from Eq. 8 with $R_{1 a}=$ $1.4 s^{-1}$, ITT $=67 \mathrm{~ms}$, and a labeling efficiency of 0.21 . Across the ventricles, the ICF rates were not uniform, and the majority of ISF flowed from the bottoms of the LV as indicated in Figs. $2 \mathrm{~h}$ and $\mathrm{k}$ with green arrows.

\section{ISF to CSF flow measured ADC-PALAN}

We performed the CSF and parenchyma optimization as a function of the PLD for ADC-PALAN shown in Fig. 3. As suggested by the b-dependent ADC measurement on the parenchyma and CSF (supplemental Fig.S1), the CSF signal was less than $1 \%$ with $b=2100 \mathrm{~s} / \mathrm{mm}^{2}$ than the signal with $b=0$. The difference between label and control parenchyma signals yielded a labeling efficiency of $0.033 \pm 0.012$. Due to the signal reduction introduced by $A D C$ and $T_{2}$, the observed labeling efficiency for parenchyma was significantly lower than those of the $\mathrm{T}_{1}$-PALAN method, which led to a much-reduced ICF signal $4.2 \pm 0.5 \times 10^{-3}(\mathrm{PLD}=1.5 \mathrm{~s})$ compared to $35 \pm 4.5 \times 10^{-3}$ $(\mathrm{PLD}=1.5 \mathrm{~s})$ in the $\mathrm{T}_{1}$-PALAN method. Eq. 8 fitted perfectly with the ICF kinetic curve and gave $\mathrm{ICF}=891 \pm 60 \mathrm{ml} / 100 \mathrm{ml} / \mathrm{min}$, and ITT $=13 \pm 2 \mathrm{~ms}$. The ICF $\Delta S$ values for the rostral and caudal LV were $3.9 \pm 1.9 \times 10^{-3}$ and $4.4 \pm 1.4 \times 10^{-3} \quad(p=0.66, n=5)$, respectively. The much lower signal obtained by the ADC-PALAN method stopped us from obtaining the ICF maps. 
The backflow from CSF to parenchyma i.e., CIF was measured with the $\mathrm{T}_{2}-\mathrm{PALAN}$ method, and the results are presented in Fig. 4. Differed from the ADC and $\mathrm{T}_{1}$ PALAN method, the CSF signal was maintained and labeled in the $T_{2}$-PALAN sequence. The CSF recovery difference between the post-labeling and the original curves with Eq. 5 gives the labeling efficiency of $0.28 \pm 0.03$. The parenchyma recovery curves after the label/control pulse (Fig. 4c) shows a barely noticeable difference, which indicates a negligible flow rate from CSF to the parenchyma. The CIF $\Delta S$ signal is under $0.22 \%$. (Fig. $4 \mathrm{~d}$ ) To obtain a reliable estimate of the ICF values, we addressed the labeled CSF strong interference and the overall low signal in the map (Fig. 4g) by performing the highresolution CIF maps with 32 averages at a slice with much fewer ventricles, i.e., $-4.1 \mathrm{~mm}$ from AC (Figs. 4h-j). The overall CIF $\Delta \mathrm{S}$ signals for the ROIs shown in Fig. $4 \mathrm{~h}$ were found to be $0.076 \pm 0.027 \%$ at $\mathrm{PLD}=2 \mathrm{~s}(\mathrm{n}=3)$ since simulation found the maximum ICF signal at $2 \mathrm{~s}$. The maximum CIF value was estimated to be $15 \pm 6 \mathrm{ml} / 100 \mathrm{mg} / \mathrm{min}$ with Eq.9, assuming ITT=0 ms, $R_{1 C S F}=0.33 s^{-1}$ and $R_{1 I S F}=0.56 s^{-1}$.

\section{Discussion}

This study proposed a series of non-invasive PALAN MRI methods to measure the ISF and CSF interchange, i.e., ICF and CIF flows, by selectively labeling ISF with $\mathrm{T}_{1}$ and ADC contrasts and CSF with $\mathrm{T}_{2}$ contrast. The $\mathrm{T}_{1}$-PALAN pulse sequence provided much higher signals than the ADC-PALAN. Both $T_{1}$-PALAN and the ADC-PALAN methods suggested that ISF flow into CSF rapidly. On the contrary, CSF to the parenchymal regions far away from ventricles was a pronouncedly slow process and barely observable with the spin labeling method.

$\mathrm{T}_{1}$-PALAN has its advantage in terms of obtaining the kinetic curves. In our study, $T_{1 \mathrm{a}}=1 / R_{1 \mathrm{a}}=0.7 \mathrm{~s}$ was found, which was far less than the parenchyma $\mathrm{T}_{1}$ relaxation time of $1.8 \mathrm{~s}$. Therefore, the bolus duration generated by the $\mathrm{T}_{1}$ module was in the order of $0.7 \mathrm{~s}$. In the ADCPALAN, the blood signal was fully suppressed by the high b value $\left(2100 \mathrm{~s} / \mathrm{mm}^{2}\right)$ and cannot be labeled. In contrast, the blood signal can fully recover during the $\mathrm{T}_{1}$ preparation module due to the blood in-flow effect and the labeling efficiency was close to one for blood. Therefore, the $\mathrm{T}_{1-}$ PALAN ICF values contained strong signal from the blood through CP, i.e., blood-cerebrospinal fluid barrier arterial spin labeling, (47) and the ICF value (1153 $\pm 270 \mathrm{ml} / 100 \mathrm{ml} / \mathrm{min})$ was higher than the value measured by the ADC-PALAN $(891 \pm 60 \mathrm{ml} / 100 \mathrm{ml} / \mathrm{min})$. The contamination from $\mathrm{CP}$ in $\mathrm{T}_{1}$-PALAN was further validated by the significantly different ICF $\Delta S$ values of the rostral and caudal LV with the $\mathrm{T}_{1}$-PALAN (Fig. 2e). The similar ICF values measured by ADC-PALAN 
in both rostral and caudal LV confirms that the observed ICF signal mainly came from ISF not blood by ADC-ALAN. (Fig. 3e)

The recent pseudo-continues ASL method has measured the blood-cerebrospinal fluid barrier (BCSFB) flow in mice to be $13-20 \mathrm{ml} / 100 \mathrm{ml} / \mathrm{min}$, i.e. a total flow of $0.52-0.8 \mu \mathrm{L} / \mathrm{min}$ by assuming LV volume $4 \mu \mathrm{L}$. (47) Gd MRI agent is unable to measure the BCSFB flow because of its inability to pass the BCSFB. However, D-glucose penetrates BCSFB with the help of abundant glucose transporter on the BCSFB. Hence dynamic glucose enhancement can be used to assess the BCSFB flow. $(36,37)$ Interestingly, the BCSFB ASL signal in mouse LV was mainly found at the top of both LV and no signal observed in $3 \mathrm{~V}$. The ICF hyperintensity regions measured by the $\mathrm{T}_{1-}$ PALAN method are visible in $3 \mathrm{~V}$ and at the bottom of the LV. (Figs. $2 \mathrm{~h}$ and $\mathrm{k}$ )

The novel non-invasive PALAN methods proposed here provided an effective tool to reveal the CSF production and circulation in the brain. Current study quantified the flow rate of ICF, i.e., $891-1153 \mathrm{ml} / 100 \mathrm{ml} / \mathrm{min}$ in LV and $3 \mathrm{~V}$. A recent invasive study on mouse brain states the CSF outflow from both $\mathrm{LV}$ and $3 \mathrm{~V}$ is in the order of magnitude of $0.1 \mu \mathrm{L} / \mathrm{min}$ (48), which is minute compare to the ICF flow obtained by our current study $(32-44 \mu \mathrm{L} / \mathrm{min}$ in $4 \mu \mathrm{L} \mathrm{LV})$. Our result indicated that the CSF secreted from parenchyma is reabsorbed by the periventricular ependymal layers as indicated in Fig. 5b. No fresh CSF is generated in this process. The reason behind rapid turnover of the CSF with the ependymal layer is under speculation. Water continuously moves in and out of the ependymal layer, a process resembles the intracellular and extracellular water movement, is one possible reason for the rapid turnover number. The difference between CSF secreted from $\mathrm{CP}(0.52-0.8 \mu \mathrm{L} / \mathrm{min})(47)$ and the total outflow $(0.1 \mu \mathrm{L} / \mathrm{min})(48)$ suggests that a large portion of the CSF in ventricles is absorbed by the surrounding parenchyma. But due to the large mass of the parenchyma, kinetically speaking, the absorption is a prolonged process (less than $15 \mathrm{ml} / 100 \mathrm{mg} / \mathrm{min}$ ) as confirmed by the T2-PALAN measurement. In Fig.4g, the strong CSF signal $(\sim 37 \%)$ obscures CIF signal of the parenchyma adjacent to the ependyma layer $(<1 \%)$, preventing us from making a solid conclusion that the CIF rate was high in those parenchyma regions. Another force that facilitates the CSF and ependymal layer exchanging process is the pulsatile nature of the CSF flux, which appears to be craniocaudally oriented during cardiac systole and in the reverse direction during diastole (49-51) This model not only explains the extremely high turnover rate of the CSF measured by PALAN method, but also perfectly explains the radioactive-labeled substances study in CSF, in which the infused tracer crosses the periventricular 
ependymal layer and can be found in the extracellular space. $(17,52,53)$ However, more work is needed to confirm the above hypothesis. One last note, in theory, $\mathrm{T}_{1}$-PALAN can also measure the backflow from CSF to parenchyma by setting a null time to parenchyma signal, but the brain white matter and gray matter have different $\mathrm{T}_{1}$ null time, making it impossible to null the entire parenchyma at the same time.

In summary, PALAN MRI methods proposed here provide technically achievable tools to examine the association between ICF and functional decline in many neurodegeneration diseases. They complement the invasive MRI method with agents and give a complete view of the ISF and CSF exchanging process.

\section{Conclusion}

We presented $\mathrm{T}_{1}, \mathrm{~T}_{2}$, and ADC PALAN schemes as new translational MRI methods to quantify in vivo ISF-CSF and CSF-ISF exchange processes in the mouse brain. PALAN offered ICF images with high sensitivity and quality. We quantified the ICF flow rate from the parenchyma to the ventricles with the $\mathrm{T}_{1}$-PALAN and the ADC-PALAN methods, which was consistent with the values measured by the MISL method. The $\mathrm{T}_{1}$-PALAN suggested the ISF exchange from ependymal layer to the parenchyma is one lagging process and is challenging to be measured by the spin labeling method.

\section{References:}

1. Abate O, Bollo E, Lotti D, Bo S. Cytological, immunocytochemical and biochemical cerebrospinal fluid investigations in selected central nervous system disorders of dogs. Zentralbl Veterinarmed B 1998;45(2):73-85.

2. Segal MB. Extracellular and cerebrospinal fluids. J Inherit Metab Dis 1993;16(4):617-638.

3. Matsumae M, Sato O, Hirayama A, Hayashi N, Takizawa K, Atsumi H, Sorimachi T. Research into the Physiology of Cerebrospinal Fluid Reaches a New Horizon: Intimate Exchange between Cerebrospinal Fluid and Interstitial Fluid May Contribute to Maintenance of Homeostasis in the Central Nervous System. Neurol Med Chir (Tokyo) 2016;56(7):416-441.

4. Oreskovic D, Klarica M. The formation of cerebrospinal fluid: nearly a hundred years of interpretations and misinterpretations. Brain Res Rev 2010;64(2):241-262.

5. Milhorat TH. Structure and function of the choroid plexus and other sites of cerebrospinal fluid formation. Int Rev Cytol 1976;47:225-288. 
6. Milhorat TH, Hammock MK, Fenstermacher JD, Levin VA. Cerebrospinal fluid production by the choroid plexus and brain. Science 1971;173(3994):330-332.

7. Bering EA, Jr., Sato O. Hydrocephalus: Changes in Formation and Absorption of Cerebrospinal Fluid within the Cerebral Ventricles. J Neurosurg 1963;20:1050-1063.

8. Tamburrini G, Caldarelli M, Di Rocco F, Massimi L, D'Angelo L, Fasano T, Di Rocco C. The role of endoscopic choroid plexus coagulation in the surgical management of bilateral choroid plexuses hyperplasia. Childs Nerv Syst 2006;22(6):605-608.

9. Hammock MK, Milhorat TH. Recent studies on the formation of cerebrospinal fluid. Dev Med Child Neurol Suppl 1973:27-34.

10. Davson H, Segal MB. Physiology of the CSF and blood-brain barriers. Boca Raton: CRC Press; 1996. 822 p. p.

11. Brown PD, Davies SL, Speake T, Millar ID. Molecular mechanisms of cerebrospinal fluid production. Neuroscience 2004;129(4):957-970.

12. Miyajima M, Arai H. Evaluation of the Production and Absorption of Cerebrospinal Fluid. Neurol Med Chir (Tokyo) 2015;55(8):647-656.

13. Brodbelt A, Stoodley M. CSF pathways: a review. Br J Neurosurg 2007;21(5):510-520.

14. Proulx ST. Cerebrospinal fluid outflow: a review of the historical and contemporary evidence for arachnoid villi, perineural routes, and dural lymphatics. Cell Mol Life Sci 2021;78(6):2429-2457.

15. Johanson CE, Duncan JA, 3rd, Klinge PM, Brinker T, Stopa EG, Silverberg GD. Multiplicity of cerebrospinal fluid functions: New challenges in health and disease. Cerebrospinal Fluid Res 2008;5:10.

16. Welch K, Friedman V. The cerebrospinal fluid valves. Brain 1960;83:454-469.

17. Casaca-Carreira J, Temel Y, Hescham SA, Jahanshahi A. Transependymal Cerebrospinal Fluid Flow: Opportunity for Drug Delivery? Mol Neurobiol 2018;55(4):2780-2788.

18. Iliff JJ, Wang M, Liao Y, Plogg BA, Peng W, Gundersen GA, Benveniste H, Vates GE, Deane R, Goldman SA, Nagelhus EA, Nedergaard M. A paravascular pathway facilitates CSF flow through the brain parenchyma and the clearance of interstitial solutes, including amyloid beta. Sci Transl Med 2012;4(147):147ra111.

19. Iliff JJ, Lee H, Yu M, Feng T, Logan J, Nedergaard M, Benveniste H. Brain-wide pathway for waste clearance captured by contrast-enhanced MRI. J Clin Invest 2013;123(3):12991309.

20. Absinta M, Ha SK, Nair G, Sati P, Luciano NJ, Palisoc M, Louveau A, Zaghloul KA, Pittaluga $S$, Kipnis J, Reich DS. Human and nonhuman primate meninges harbor lymphatic vessels that can be visualized noninvasively by MRI. Elife 2017;6.

21. Ahn JH, Cho H, Kim JH, Kim SH, Ham JS, Park I, Suh SH, Hong SP, Song JH, Hong YK, Jeong $\mathrm{Y}$, Park SH, Koh GY. Meningeal lymphatic vessels at the skull base drain cerebrospinal fluid. Nature 2019;572(7767):62-66.

22. Xu Z, Xiao N, Chen Y, Huang H, Marshall C, Gao J, Cai Z, Wu T, Hu G, Xiao M. Deletion of aquaporin-4 in APP/PS1 mice exacerbates brain Abeta accumulation and memory deficits. Mol Neurodegener 2015;10:58.

23. Xie L, Kang H, Xu Q, Chen MJ, Liao Y, Thiyagarajan M, O'Donnell J, Christensen DJ, Nicholson C, Iliff JJ, Takano T, Deane R, Nedergaard M. Sleep drives metabolite clearance from the adult brain. Science 2013;342(6156):373-377. 
24. Rasmussen MK, Mestre $\mathrm{H}$, Nedergaard $\mathrm{M}$. The glymphatic pathway in neurological disorders. The Lancet Neurology 2018;17(11):1016-1024.

25. Louveau A, Da Mesquita S, Kipnis J. Lymphatics in Neurological Disorders: A NeuroLympho-Vascular Component of Multiple Sclerosis and Alzheimer's Disease? Neuron 2016;91(5):957-973.

26. Harrison IF, Siow B, Akilo AB, Evans PG, Ismail O, Ohene $Y$, Nahavandi $P$, Thomas DL, Lythgoe MF, Wells JA. Non-invasive imaging of CSF-mediated brain clearance pathways via assessment of perivascular fluid movement with diffusion tensor MRI. Elife 2018;7.

27. Taoka T, Masutani Y, Kawai H, Nakane T, Matsuoka K, Yasuno F, Kishimoto T, Naganawa S. Evaluation of glymphatic system activity with the diffusion MR technique: diffusion tensor image analysis along the perivascular space (DTI-ALPS) in Alzheimer's disease cases. Jpn J Radiol 2017;35(4):172-178.

28. Kuo PH, Stuehm C, Squire S, Johnson K. Meningeal Lymphatic Vessel Flow Runs Countercurrent to Venous Flow in the Superior Sagittal Sinus of the Human Brain. Tomography 2018;4(3):99-104.

29. Da Mesquita S, Louveau A, Vaccari A, Smirnov I, Cornelison RC, Kingsmore KM, Contarino C, Onengut-Gumuscu S, Farber E, Raper D, Viar KE, Powell RD, Baker W, Dabhi N, Bai R, Cao R, Hu S, Rich SS, Munson JM, Lopes MB, Overall CC, Acton ST, Kipnis J. Functional aspects of meningeal lymphatics in ageing and Alzheimer's disease. Nature 2018;560(7717):185-191.

30. Gaberel T, Gakuba C, Goulay R, Martinez De Lizarrondo S, Hanouz JL, Emery E, Touze E, Vivien D, Gauberti M. Impaired glymphatic perfusion after strokes revealed by contrastenhanced MRI: a new target for fibrinolysis? Stroke 2014;45(10):3092-3096.

31. Lee H, Mortensen K, Sanggaard S, Koch P, Brunner H, Quistorff B, Nedergaard M, Benveniste H. Quantitative Gd-DOTA uptake from cerebrospinal fluid into rat brain using 3D VFA-SPGR at 9.4T. Magn Reson Med 2018;79(3):1568-1578.

32. Stanton EH, Persson NDA, Gomolka RS, Lilius T, Sigurethsson B, Lee H, Xavier ALR, Benveniste $\mathrm{H}$, Nedergaard M, Mori Y. Mapping of CSF transport using high spatiotemporal resolution dynamic contrast-enhanced MRI in mice: Effect of anesthesia. Magn Reson Med 2021;85(6):3326-3342.

33. Ringstad G, Valnes LM, Dale AM, Pripp AH, Vatnehol SS, Emblem KE, Mardal KA, Eide PK. Brain-wide glymphatic enhancement and clearance in humans assessed with $\mathrm{MRI} . \mathrm{JCl}$ Insight 2018;3(13).

34. Eide PK, Ringstad G. MRI with intrathecal MRI gadolinium contrast medium administration: a possible method to assess glymphatic function in human brain. Acta Radiol Open 2015;4(11):2058460115609635.

35. Ringstad G, Vatnehol SAS, Eide PK. Glymphatic MRI in idiopathic normal pressure hydrocephalus. Brain 2017;140(10):2691-2705.

36. Chen L, Wei Z, Chan KW, Li Y, Suchal K, Bi S, Huang J, Xu X, Wong PC, Lu H, van ZijI PC, Li $\mathrm{T}, \mathrm{Xu}$ J. D-Glucose uptake and clearance in the tauopathy Alzheimer's disease mouse brain detected by on-resonance variable delay multiple pulse MRI. J Cereb Blood Flow Metab 2021;41:1013-1025.

37. Huang J, van Zijl PCM, Han X, Dong CM, Cheng GWY, Tse KH, Knutsson L, Chen L, Lai JHC, Wu EX, Xu J, Chan KWY. Altered d-glucose in brain parenchyma and cerebrospinal fluid 
of early Alzheimer's disease detected by dynamic glucose-enhanced MRI. Sci Adv 2020;6(20):eaba3884.

38. Ellingson BM, Kim E, Woodworth DC, Marques H, Boxerman JL, Safriel Y, McKinstry RC, Bokstein F, Jain R, Chi TL, Sorensen AG, Gilbert MR, Barboriak DP. Diffusion MRI quality control and functional diffusion map results in ACRIN 6677/RTOG 0625: a multicenter, randomized, phase II trial of bevacizumab and chemotherapy in recurrent glioblastoma. Int J Oncol 2015;46(5):1883-1892.

39. Kim SG. Quantification of relative cerebral blood flow change by flow-sensitive alternating inversion recovery (FAIR) technique: application to functional mapping. Magn Reson Med 1995;34(3):293-301.

40. Wang JN, Yarnykh VL, Yuan C. Enhanced Image Quality in Black-Blood MRI Using the Improved Motion-Sensitized Driven-Equilibrium (iMSDE) Sequence. J Magn Reson Imaging 2010;31(5):1256-1263.

41. Mao J, Mareci TH, E.RAndrew. Experimental study of optimal selective $180^{\circ}$ radiofrequency pulses. J Magn Reson 1988;79(1):1-10.

42. Lein ES, Hawrylycz MJ, Ao N, Ayres M, Bensinger A, Bernard A, Boe AF, Boguski MS, Brockway KS, Byrnes EJ, Chen L, Chen L, Chen TM, Chin MC, Chong J, Crook BE, Czaplinska A, Dang CN, Datta S, Dee NR, Desaki AL, Desta T, Diep E, Dolbeare TA, Donelan MJ, Dong HW, Dougherty JG, Duncan BJ, Ebbert AJ, Eichele G, Estin LK, Faber C, Facer BA, Fields R, Fischer SR, Fliss TP, Frensley C, Gates SN, Glattfelder KJ, Halverson KR, Hart MR, Hohmann JG, Howell MP, Jeung DP, Johnson RA, Karr PT, Kawal R, Kidney JM, Knapik RH, Kuan CL, Lake JH, Laramee AR, Larsen KD, Lau C, Lemon TA, Liang AJ, Liu Y, Luong LT, Michaels J, Morgan JJ, Morgan RJ, Mortrud MT, Mosqueda NF, Ng LL, Ng R, Orta GJ, Overly CC, Pak TH, Parry SE, Pathak SD, Pearson OC, Puchalski RB, Riley ZL, Rockett HR, Rowland SA, Royall JJ, Ruiz MJ, Sarno NR, Schaffnit K, Shapovalova NV, Sivisay T, Slaughterbeck CR, Smith SC, Smith KA, Smith BI, Sodt AJ, Stewart NN, Stumpf KR, Sunkin SM, Sutram M, Tam A, Teemer CD, Thaller C, Thompson CL, Varnam LR, Visel A, Whitlock RM, Wohnoutka PE, Wolkey CK, Wong VY, Wood M, Yaylaoglu MB, Young RC, Youngstrom BL, Yuan XF, Zhang B, Zwingman TA, Jones AR. Genome-wide atlas of gene expression in the adult mouse brain. Nature 2007;445(7124):168-176.

43. Lin Z, Jiang D, Liu D, Li Y, Uh J, Hou X, Pillai JJ, Qin Q, Ge Y, Lu H. Noncontrast assessment of blood-brain barrier permeability to water: Shorter acquisition, test-retest reproducibility, and comparison with contrast-based method. Magn Reson Med 2021;86(1):143-156.

44. Calamante F. Arterial input function in perfusion MRI: a comprehensive review. Progress in Nuclear Magnetic Resonance Spectroscopy 2013:DO:

10.1016/j.pnmrs.2013.1004.1002.

45. Wong EC, Buxton RB, Frank LR. A theoretical and experimental comparison of continuous and pulsed arterial spin labeling techniques for quantitative perfusion imaging. Magn Reson Med 1998;40(3):348-355.

46. Qin Q, Huang AJ, Hua J, Desmond JE, Stevens RD, van Zijl PCM. Three-dimensional whole-brain perfusion quantification using pseudo-continuous arterial spin labeling MRI at multiple post-labeling delays: accounting for both arterial transit time and impulse response function. NMR Biomed 2014;27(2):116-128. 
47. Evans PG, Sokolska M, Alves A, Harrison IF, Ohene $\mathrm{Y}$, Nahavandi P, Ismail O, Miranda E, Lythgoe MF, Thomas DL, Wells JA. Non-Invasive MRI of Blood-Cerebrospinal Fluid Barrier Function. Nat Commun 2020;11(1):2081.

48. Liu G, Mestre H, Sweeney AM, Sun Q, Weikop P, Du T, Nedergaard M. Direct Measurement of Cerebrospinal Fluid Production in Mice. Cell Rep 2020;33(12):108524.

49. Enzmann DR, Pelc NJ. Normal flow patterns of intracranial and spinal cerebrospinal fluid defined with phase-contrast cine MR imaging. Radiology 1991;178(2):467-474.

50. Nitz WR, Bradley WG, Jr., Watanabe AS, Lee RR, Burgoyne B, O'Sullivan RM, Herbst MD. Flow dynamics of cerebrospinal fluid: assessment with phase-contrast velocity MR imaging performed with retrospective cardiac gating. Radiology 1992;183(2):395-405.

51. Vivas-Buitrago T, Lokossou A, Jusue-Torres I, Pinilla-Monsalve G, Blitz AM, Herzka DA, Robison J, Xu J, Guerrero-Cazares H, Mori S, Quinones-Hinojosa A, Baledent O, Rigamonti D. Aqueductal Cerebrospinal Fluid Stroke Volume Flow in a Rodent Model of Chronic Communicating Hydrocephalus: Establishing a Homogeneous Study Population for Cerebrospinal Fluid Dynamics Exploration. World Neurosurg 2019;128:e1118-e1125.

52. Bowsher D. Pathways of absorption of protein from the cerebrospinal fluid: an autoradiographic study in the cat. Anat Rec 1957;128(1):23-39.

53. Sahar A, Hochwald GM, Sadik AR, Ransohoff J. Cerebrospinal fluid absorption in animals with experimental obstructive hydrocephalus. Arch Neurol 1969;21(6):638-644.
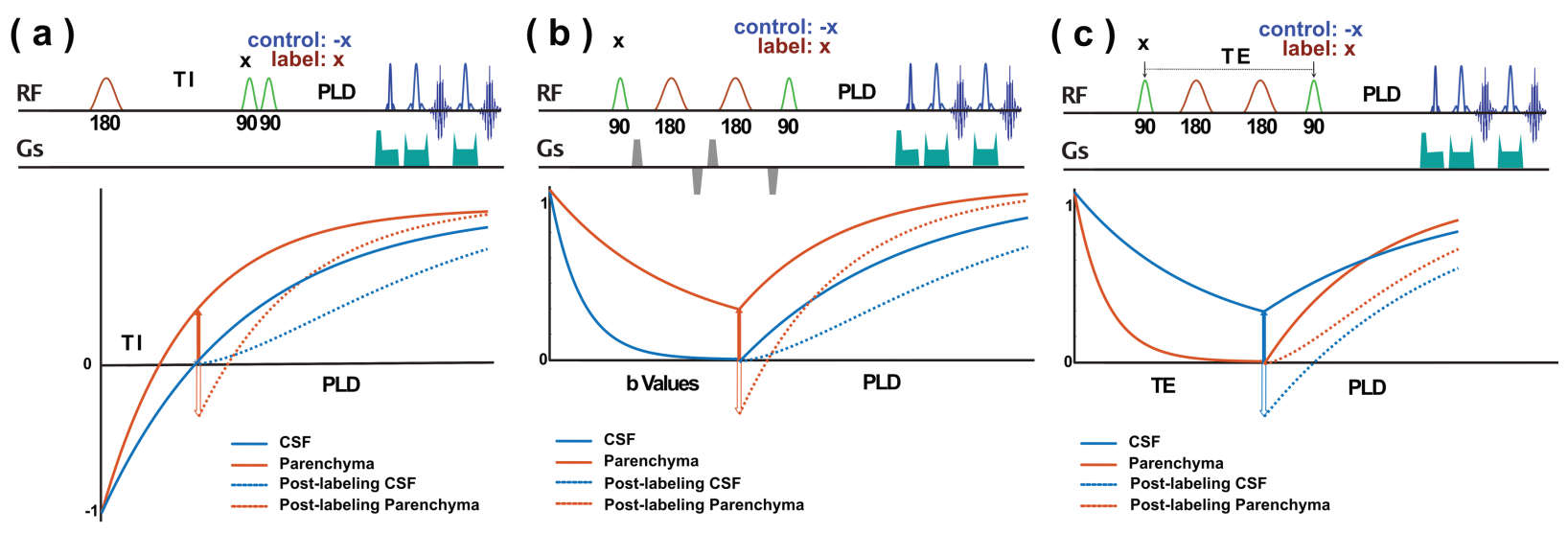

Figure 1. (a) Illustration of the $T_{1}$-based phase alternate labeling with null recovery ( $\left.T_{1}-P A L A N\right)$ sequence. The signal changes of CSF and parenchyma without labeling are solid lines, after labeling are dashed lines. After the inverting pulse, at the CSF null time, a pair of 90-degree pulses, i.e., Z-filter, is apply. The phase of the second 90-degree pulse in the Z-filter is alternated and can flip the parenchyma longitudinal magnetization up (control) and down (label). The difference between the dashed and the solid CSF recovery curves is due to the ISF-CSF exchange. A TSE MRI with long echo time (LE-TSE) is implemented to readout the CSF signal and to suppress the 
parenchyma signal. (b) Illustration of the apparent diffusion coefficient-based phase alternate labeling with null recovery (ADC-PALAN) sequence. The signal changes of CSF and parenchyma without labeling are solid lines, after labeling are dashed lines. An improved motion-sensitized driven-equilibrium (iMSDE) module is applied to suppress the CSF signal with high $b$ values, while strong parenchyma signal is preserved. The phase of the second 90-degree pulse in the iMSDE is alternated to flip the parenchyma longitudinal magnetization up (control) and down (label). Similar to $\mathrm{T}_{1}$-PALAN, the ISF-CSF exchanging process introduces the difference in CSF recovery curves and LE-TSE is used for the CSF imaging. (c) Illustration of the $\mathrm{T}_{2}$-based phase alternate labeling with null recovery (T2-PALAN) method. The signal changes of CSF and parenchyma without labeling are solid lines, after labeling are dashed lines. Like the ADC-PALAN, a Carr-Purcell-Meiboom-Gill (CPMG) module is applied to null the ISF signal. The recovery curve of ISF is modulated by the flow from CSF to ISF. 



Figure 2. (a) Averaged parenchyma recovery curves for the whole slice post control/label pulse $(n=3)$ as a function of the post labeling time (PLD) for the $T_{1}$ based null recovery with phase alternate labeling ( $\mathrm{T}_{1}$-PALAN) sequence. (b) The difference between control and label of the parenchyma recovery curves. Solid line is theoretical fitting curves with Eq.4 $\left(\mathrm{R}^{2}=0.97\right)$. (c) Averaged CSF recovery curves for lateral ventricle (LV) and the third ventricle (3V) with the post control/label pulse $(n=3)$ as a function of the PLD for the $T_{1}$-PALAN sequence. (d) The difference of the averaged CSF recovery curves, i.e. the ISF-CSF flow (ICF) kinetic curve, as an function of 
PLD. Solid line is theoretical fitting curves with Eq.8 $\left(\mathrm{R}^{2}=0.99\right)$. (e) The ICF $\Delta S$ values for the rostral and caudal LV. (f, i) The high-resolution $\mathrm{T}_{2}$ weighted images by LE-TSE for the two slices collected. Choroid plexuses (CP) are indicated with green arrows. (g, j) The typical control images for $\mathrm{T}_{1}$-PALAN method. (h, $\mathrm{k}$ ) The corresponding ICF maps acquired with $\mathrm{T}_{1}$-PALAN. The regions with hyperintensity ICF values are indicated with green arrows.
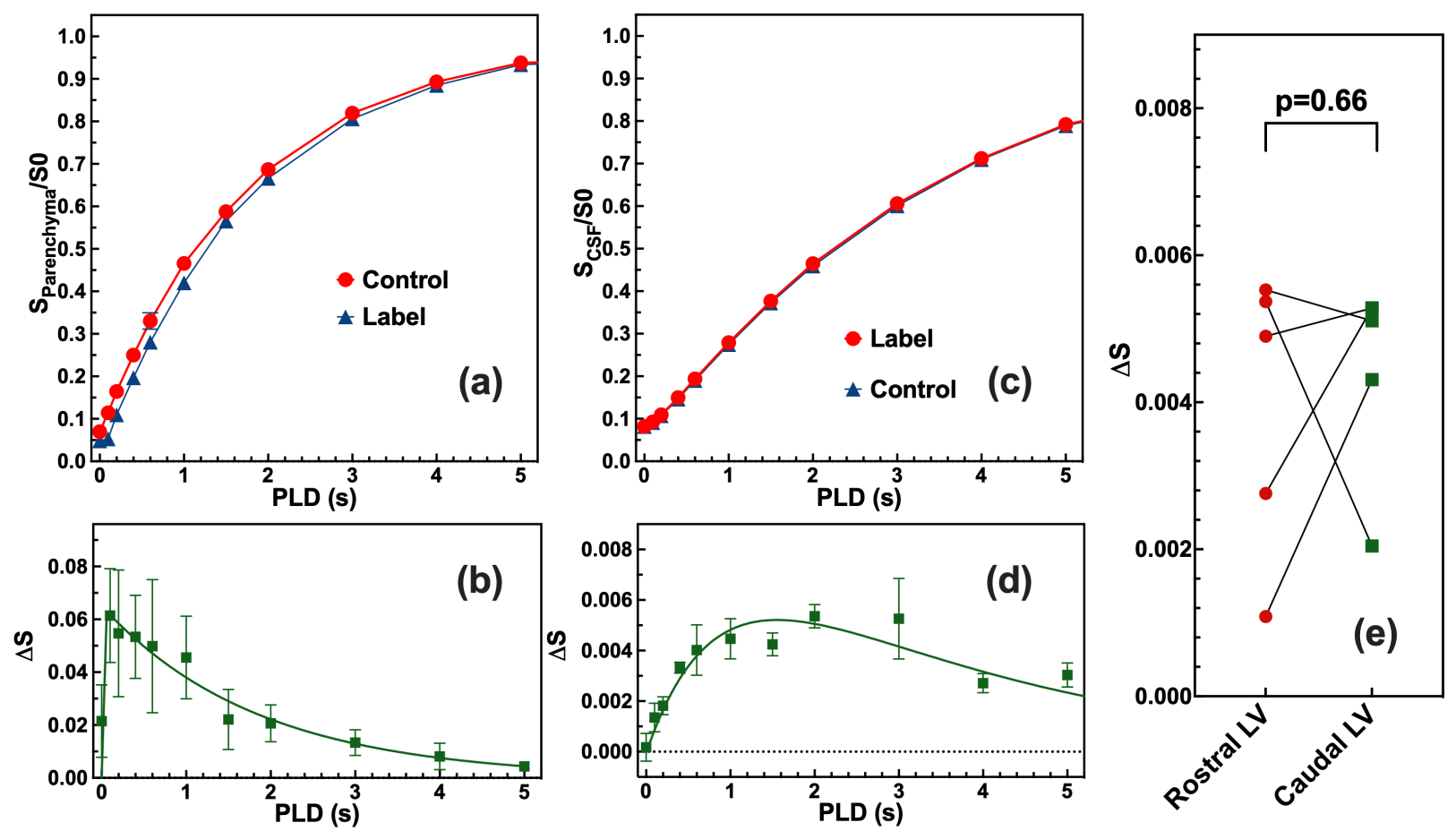

Figure 3. (a) Averaged parenchyma recovery curves for the whole slice after the control/label pulse $(n=3)$ as a function of the post labeling time (PLD) for the apparent diffusion coefficient based null recovery with phase alternate labeling (ADC-PALAN) sequence. (b) The difference of the parenchyma recovery curves. Solid line is the theoretical fitting curve in Eq.4 $\left(\mathrm{R}^{2}=0.97\right)$. (c) Averaged CSF recovery curves with the control/label pulse $(n=3)$ as a function of the PLD for the ADC-PALAN sequence. (d) The difference of the averaged CSF recovery curves, i.e. the ISF-CSF flow (ICF) kinetic curve, as a function of PLD. Solid line is theoretical fitting curves with Eq.8 $\left(\mathrm{R}^{2}=0.95\right)$. (e) The ICF $\Delta S$ values for the rostral and caudal lateral ventricle (LV). 

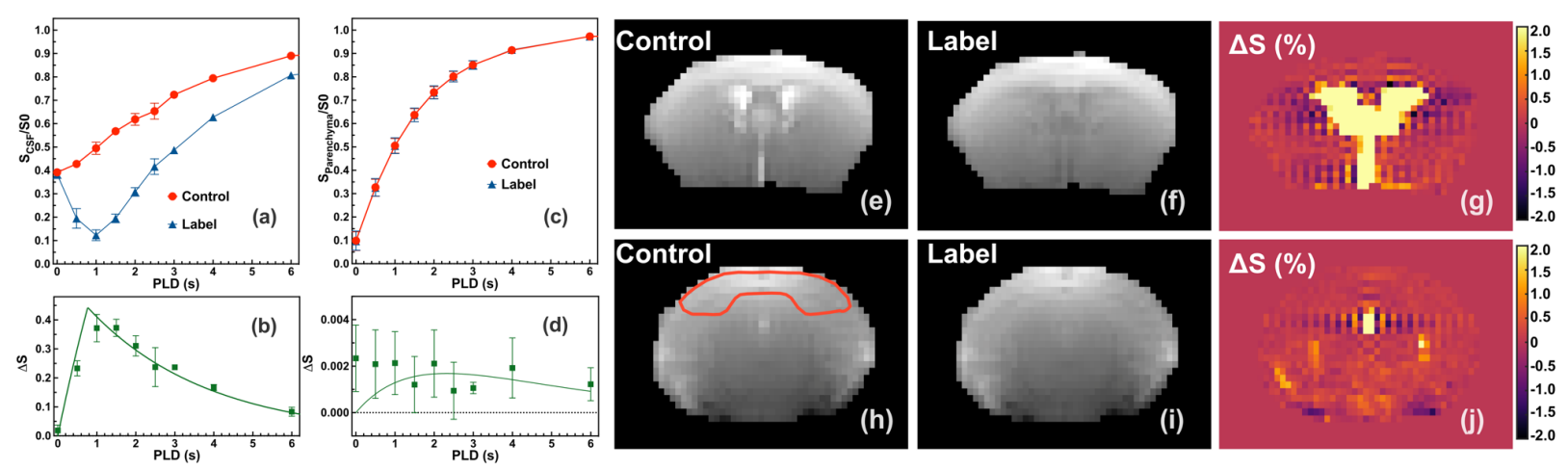

Figure 4. (a) Averaged CSF recovery curves for the CSF in ventricles after the control/label pulse $(n=3)$ as a function of the post labeling time (PLD) for the $T_{2}$ based null recovery with phase alternate labeling ( $\mathrm{T}_{2}$-PALAN) sequence. (b) The difference of the CSF recovery curves. Solid line is the theoretical fitting curve with Eq.5 $\left(\mathrm{R}^{2}=0.93\right)$. A label efficiency 0.28 was obtained from the fitting. (c) Averaged parenchyma recovery curves with the control/label pulse $(n=3)$ as a function of the PLD for the $T_{2}$-PALAN sequence. (d) The difference of the averaged parenchyma recovery curves ( $\mathrm{n}=3$ ), i.e. the CSF-ISF flow (CIF) kinetic curve, as an function of PLD. Solid line is the simulated curve using Eq.9 by assuming ICF $=20 \mathrm{ml} / 100 \mathrm{mg} / \mathrm{min}$, ITT=0 $\mathrm{ms}, R_{1 C S F}=$ $0.33 s^{-1}$ and $R_{1 I S F}=0.56 s^{-1}$. The typical control $\left(\mathrm{e}, \mathrm{h}\right.$ ) and label images (f, i) by the $\mathrm{T}_{2}$-PALAN method for two slices. The CIF $\Delta S$ maps obtained by $\mathrm{T}_{2}$-PALAN method following Eq. 9 for PLD $=2 \mathrm{~s}(\mathrm{~g}, \mathrm{j})$. The typical ROIs used for extracting CIF $\Delta S$ values are indicated in (h). 


\section{Brain Parenchyma}

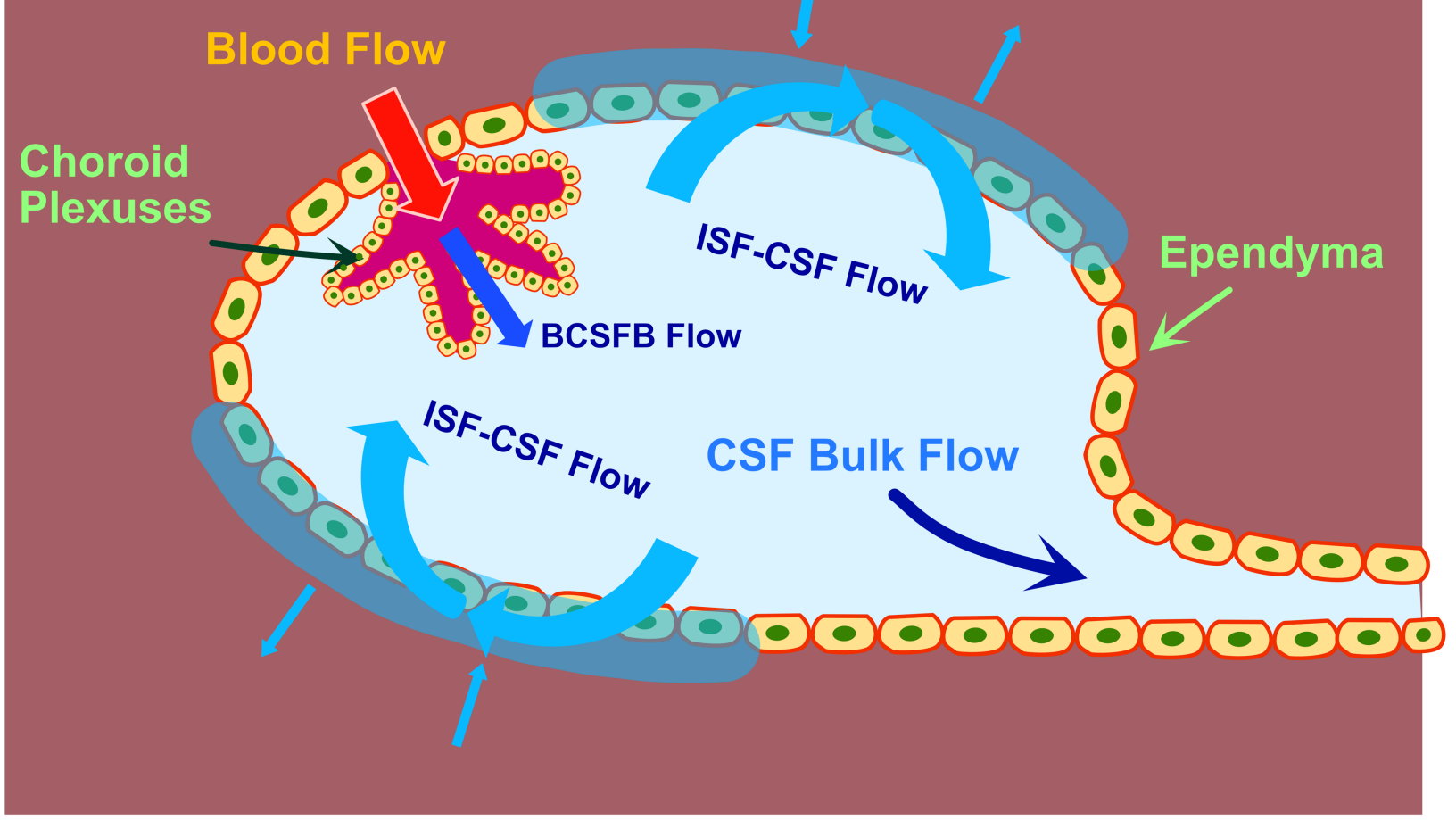

Figure 5. The schematic diagram of the CSF flow in ventricles revealed by the PALAN methods. CSF is primarily secreted from the choroid plexuses (CP) provided by the anterior choroidal arterial blood. There is a rapid exchange between the interstitial fluid (ISF) in the ependymal layer and the CSF in the ventricles. However, the exchanging process from the ependymal layer to the regions far away from ependyma is an extremely slow process. Eventually, CSF flows out of ventricles and exits into the subarachnoid space (SAS) at the cisterna magna. 